\title{
2006-639: AN ENGINEERING RESEARCH EXPERIENCE FOR TEACHERS: IMPLEMENTATION AND ASSESSMENT
}

\section{Anant Kukreti, University of Cincinnati}

ANANT R. KUKRETI, Ph.D., is a Professor and Head of the Department of Civil and Environmental Engineering at the University of Cincinnati (UC). He joined UC on 8/15/00 and before that worked 22 years at University of Oklahoma. He teaches structural engineering, with research in experimental and finite element analysis of structures. He has won major teaching awards and is internationally recognized in his primary research field.

\section{Patricia McNerney, University of Cincinnati}

PATTY D. MCNERNEY, Doctoral Student in C \& I Education/Technology, College of Education, Criminal Justice, and Human Services, UC. She has spent the last 15 years in the K-12 education arena with teaching experience in the areas of math, science, technology and served as district technology director. Her research is focused in two areas: integration of emerging technology into education and teacher training.

\section{Suzanne Soled, University of Cincinnati}

SUZANNE W. SOLED, Ph.D. Associate Professor, Educational Foundations, College of Education, Criminal Justice, and Human Services, UC. Dr. Soled teaches undergraduate and graduate courses in assessment and evaluation, and cognitive psychology. Her research is focused in two areas: teaching and learning, and assessment and evaluation. She has won the Outstanding Teaching Award in the College of Education.

\section{Kelly Obarski, University of Cincinnati}

KELLY J. OBARSKI, Doctoral Student in C \& I Education/Technology, College of Education, Criminal Justice, and Human Services, UC. Along with teaching undergraduate and graduate education course work, Kelly is currently researching how participation in a NSF Fellowship affects undergraduate and graduate Fellows career choices once they leave the project.

\section{Mingming Lu, University of Cincinnati}

MINGMING LU, Ph.D., Assistant Professor, Department of Civil and Environmental Engineering, UC. Dr. Lu teaches undergraduate and graduate courses in environmental engineering. For research she has specialized in air sampling and compositional analysis of aerosols, and the characterization of diesel particulate matter.

\section{Richard Miller, University of Cincinnati}

RICHARD A. MILLER, Ph.D, Professor, Department of Civil and Environmental Engineering, UC. Dr. Miller teaches graduate and undergraduate courses in civil engineering materials, structural engineering. His main research focus is concrete materials, prestressed and reinforced concrete, and testing and evaluation of structures and bridges.

\section{Daniel Oerther, University of Cincinnati}

DANIEL B. OERTHER, Associate Professor, Department of Civil and Environmental Engineering, UC. Dr. Oerther teaches graduate and undergraduate courses in biology and molecular biology and applications to natural and engineered environments. His research focuses upon microorganisms in wastewater treatment plants, drinking water treatment plants, bioremediation field sites, and natural surface watershed. 
UC. Dr. Wei teaches graduate and undergraduate courses in transportation engineering. His research includes Intelligent Transportation Systems (ITS), traffic flow characteristics and microscopic traffic simulation modeling.

\section{Thaddeus Fowler, University of Cincinnati}

THADDEUS FOWLER, PhD., is a Professor Emeritus, Division of Teacher Education, College of Education, Criminal Justice, and Human Services, UC. Dr. Fowler has taught instructional methods courses at UC for 27 years, and has close relationships with many school districts. His administrative positions include program coordinator, director, and associate division head. He has worked as a consultant to technical corporations to develop their in-house training programs. 


\section{An Engineering Research Experience for Teachers: Implementation and Assessment}

\section{Introduction}

This paper describes the research and professional development experience provided in a pilot Site for $7^{\text {th }}$ to $12^{\text {th }}$ grade teachers in "Civil Engineering" with a special focus on "Civil Infrastructure Renewal and Rehabilitation." The Site was offered at the Department of Civil and Environmental Engineering (CEE), University of Cincinnati (UC) during the summer of 2005. This Research Experiences for Teachers (RET) Site was funded by the National Science Foundation (NSF) and can be found at http://www.eng.uc.edu/STEP/ret/. The goals of this RET experience were three fold. First, we expected to educate, cultivate, and facilitate $7^{\text {th }}$ to $12^{\text {th }}$ grade science and math teachers by exploring the scientific method of inquiry and the critical research skills that engineers use to solve open-ended real-world problems. Second, it was expected that the teachers participating in the RET experience would become role models by applying their research experiences in their classrooms and with colleagues. Third, the teachers' new skills would enable $7^{\text {th }}$ to $12^{\text {th }}$ grade students to directly link their standards-based education to events and issues occurring within their community and encourage them to become effective citizens in a technology-driven society. This paper describes four aspects to the project; first the research projects and professional development activities executed are presented, second the assessment process used as part of the evaluation plan is described, third the outcomes of the evaluation plan are presented and how these results obtained are planned to be used for future improvements, and finally the general conclusions from the whole experience are summarized. Hopefully, this documentation will help others in planning similar experiences for K-12 teachers.

In a world with rapidly changing technology and a global economy, there is a growing concern that Americans will not remain competitive ${ }^{1}$. The well being of our nation depends upon how well we educate our children in science, technology, engineering, and mathematics (STEM). Poorly prepared instructors teach many STEM classes, and our inability to attract and keep good teachers has become problematic ${ }^{2-7}$. The most effective way to interest children in science and math is by producing enthusiastic inspiring teachers. Teacher training is not simply a matter of preparation; it depends just as much on sustained, high-quality professional development $^{8-12}$. The RET Site provided the type of quality professional development that encouraged reciprocal interactions between teachers and professionals necessary in today's economy to open channels of communication and sharing to enhance and maintain teacher abilities and preparation for teaching relevant STEM skills to students in an emerging global economy.

As part of the RET Site, each teacher worked from 8:00 a.m. to noon each day with a CEE faculty member and a dedicated graduate student on a research project for six weeks during the summer in their laboratories. In the afternoon from 1:00 to 5:00 p.m. the teachers took professional development seminars taught by education and engineering faculty members and practicing engineers, and went on four field trips. They also worked with a team of engineering and education graduate Fellows working for a NSF Graduate K-12 Fellows Grant to develop lesson plans that would be implemented in their classrooms before they finished the summer RET summer experience. They presented their research findings and a related lesson activity 
they plan to teach in the following academic year to a panel of three professional engineers at the end of the summer. Each of the teachers received three Continuing Education Unit credits for the combined summer research and professional development experience. The teachers received a stipend of $\$ 3,500$ for participating in the six week summer RET Site. Also upon returning to school, the teachers will prepare at least one paper for presentation at a regional/national teacher education conference, and implement their experience in at least one course taught by them during the next year. For post RET implementation the teachers will receive a stipend of $\$ 1,500$ and a project supplies budget of $\$ 500$. The project evaluation plan includes assessment of both the impact of the research experience on the teacher and on student learning after the teacher classroom implementation. Each of these elements of the RET Site will be explained in detail in the paper, and a brief description follows in this paper.

\section{Research Experience Provided}

Today's civil engineers face the grand challenge of updating the nation's infrastructure, which is vital to its economy, security, and international competitiveness, and to provide for expanding populations while maintaining a balance between cost and adverse environmental effects. To address these critical needs, the research areas in the Department of CEE at UC focus on infrastructure renewal and environmental issues: two national priorities. Each year over 100 research grants are executed with a total budget of $\$ 17.5$ Million and annual research expenditures of over \$6.5 Million. Twenty-one research laboratories (8 in Civil and 13 in Environmental Engineering) allow bench-scale to full-scale testing of a variety of systems. State-of-the-art software is available for simulation, computer aided design, statistical analysis, and visualization of large data. Thus, with the evolution of this research funding and labs, and the regular mainstream graduate program, CEE with the support of the NSF in the form of a RET Site, enlarged the scope of its research program by introducing promising $7^{\text {th }}$ to $12^{\text {th }}$ grade teachers in research in civil infrastructure engineering with the expectation this exposure will motivate them to become critical thinkers, apply science to daily living, use civil infrastructure examples as a context to convey math and science concepts, and encourage their students to consider engineering careers.

Four research project topics were chosen to provide an overall view on the research related to performance evaluation, health monitoring, and rehabilitation of civil infrastructure systems, which included: 1) construction and performance enhancement of city bridge structures; 2) biotechniques to make "more" drinking water available; 3 ) control of air pollution caused by trucks, buses and machines; and 4) simulation techniques to address transportation congestion and traffic management problems in an urban city. The basic approach used in each was discovery through actual construction and experimental testing, field data collection, observing and recording, computer simulations, synthesizing, generalizations, and reflection on classroom integration. A brief description of the projects follows.

"Monitoring Precast-Prestressed Concrete Deck Panels on a Steel Girder Bridge": The purpose of the project was to evaluate methods for reducing the "down time" for bridge construction. Precast concrete elements offer a solution. The problem is that over a long period of time, the concrete changes shape due to temperature, stress, creep, and shrinkage. These dimensional changes may cause the panels to come loose or cause the joints to crack and leak. 
This project monitored the response of the panels to temperature, the long term dimensional changes in the panels, and conduct periodic load tests to assess composite action. The portion of the project that the teacher was involved with was to determine the creep, shrinkage, and temperature properties of the grout used in the joints of the panels described above, and to assist with a load test of the bridge.

"Environmental Sustainability: Drinking Water Purification and Waste Water Treatment": The objective of this research project was to use existing "high" tech solutions for environmental engineering and adapt them to improve the environmental health in the developing world. These adaptations will be used to improve water quality and quantity, increase water reuse and sustainability and to protect the public heath of the individuals within the village of Roche, Tanzania. The project was coordinated with the help of the Village Life Outreach Program. This study involved looking at several options for drinking water purification technologies that can be made using materials available in the village. These options were then narrowed and tested to determine the feasibility and sustainability of each option. Testing was done to determine if the technology is effective in removing particulates and pathogenic agents that cause the health problems in this village.

"Diesel Emissions from Biodiesel Fuel": According to the EPA Health Assessment of Diesel Exhaust diesel emissions, composed of particulate matter (PM) and gases, can harm not only individuals, but also the environment. Since the hazards of diesel emissions have been studied, new ideas have been researched and implemented to reduce harmful diesel emissions. Biodiesel is one method that is currently being utilized as a cleaner alternative fuel to diesel. This project involved researching and experimenting with biodiesel with following two goals in mind: 1) to compare emissions of normal diesel and biodiesel; and 2) to investigate the characteristics of biodiesel. More specifically the project focused on the PM emissions for normal diesel and biodiesel. The gas emissions were analyzed by determining the concentrations of $\mathrm{CO}$ and $\mathrm{NO}_{\mathrm{x}}$. Lastly, samples were collected for the organic carbon and elemental carbon concentration determination. These three methods of analysis aided in the investigation of both the characteristics of biodiesel that make it a clean alternative fuel and the comparison data for normal diesel and biodiesel.

“Impact Analysis of Intelligent Transportation System (ITS) Infrastructure”: The US Department of Transportation has launched new Intelligent Transportation Systems (ITS) initiatives aimed at improving transportation safety, relieving congestion and enhancing productivity, which use computer-based analysis/simulation models as its brain (intelligent system). This project was designed to show teachers how these models are used for analyzing and evaluating operational impact of ITS alternatives on traffic flow by adjusting traffic signals and other ITS controlled variables, based on real-time information to help move traffic at higher average speeds and better adhere to schedules. Unlike the other three projects, this project showed how computer simulated learning occurs. The teacher was first introduced to the basic theories and fundamentals of traffic simulation by using the Highway Capacity Manual (HCM)based software as a teaching tool. For selected freeway ramp sites and immediately following arterial intersection(s) in Cincinnati, the teacher studied the traffic flow in a short segment of the freeway to understand what variables impact the traffic flow patterns. Using the facilities available at the Advanced Transportation Engineering Systems Laboratory, the teacher was then 
trained on the use of VISSIM traffic simulation software, and conducted simulation studies for the previously selected sites to evaluate their operational performance under the existing and future traffic conditions. The teacher identified existing and potential traffic problems by analyzing the results obtained from both the HCM-based and VISSIM simulators, in terms of "measure of effectiveness" estimation, and recommend possible improvements for HCM models.

A field trip connected with each research project was organized for all teachers, and included the following: 1) Hamilton County Department of Environmental Services laboratories that regulate and monitor the air quality and solid waste; 2) Greater Cincinnati Water Works Miller Treatment Plant; 3) Advanced Regional Traffic Interactive Management and Information System (ARTIMS) Center in Cincinnati; and 4) a Prestressed Concrete Plant in Northern Kentucky. The four field trips enhanced the teachers' background knowledge concerning both the government and private sector roles of civil engineering. It also provided an opportunity for them to interact with engineers working in these two sectors and develop relationships for future interactions between entities, students, and teachers. Teachers attended field trips with CEE faculty members and dedicated graduate students, participating in debriefing after the trips. Resources were gathered and a paper was produced after each field trip for future reference.

Each teacher developed a detailed lesson plan tied to state technology and content standards connected with their research and a poster, which they intended to present at their school upon return. These included the following: 1) Penny Overload - Modeling Load and Deflection of a Bridge; 2) To Drink or Not to Drink to Drink - Learning Science and Engineering at the Hughes Center; 3) Dirty Diesel: Implementation of RET Research in the Classroom; and 4) Transportation Engineering - Is It For You? The National Educational Technology Plan ${ }^{13}$ holds that students of all ages are technologically more literate than most of their teachers and would rather utilize advanced technology to learn. The lessons developed by RET teachers work towards demonstrating how highly qualified teachers integrate advanced technology, STEM skills, and academic standards joining them in creative and challenging ways for high-level technical capabilities and motivation of their students, while also achieving alignment with the National Educational Technology Plan ${ }^{13}$.

\section{Professional Development}

The professional development program supported development of highly qualified teachers and included a series of seminars given by the Civil and Environmental Engineering and College of Engineering faculty members and professional practicing engineers to make the teachers aware of: 1) opportunities the engineering field of study and professional practice, and Civil Engineering in particular, offers to use as a context to teach topics in mathematics and science; 2) authentic teaching practices and assessment of how learning occurs when used; and 3 ) ideas and resources available for lesson plans and grant writing. Each of the engineering seminars included following three elements: 1) skills sets and educational training needed; 2) practice of engineering with examples of actual real-world projects; and 3) examples and resources available that can be used in the K-12 classrooms. All seminars were held from 1:00 to 5:00 p.m. with a break in between. All seminars allowed time for direct two-way interaction between the professional engineers and teachers to address teacher specific needs. A brief 
description of the contents of these engineering seminars is presented below to provide ideas for others planning similar ones:

1. Introduction to Engineering: A civil engineering faculty member presented an overview of the profession of engineering, and civil engineering in particular. Examples on how laboratory test results for commonly used civil engineering construction materials can be used as a context to teach various topics in mathematics and science were presented. Statistical analysis procedures used to develop design code requirements were discussed. How civil engineers use this information for design and safety were discussed. The presentation showcased the engineering design process.

2. Biodiesel Retrofit of Busses: This presentation was given by the Administrative Coordinator of the Hamilton County Department of Environmental Services and included information on the history of biodiesel fuel, its basic constituents, functioning of the biodiesel engine, advantages and disadvantages of using biodiesel, projects funded in Hamilton County to retrofit school busses, opportunities available to teachers to apply for funding, and ideas for lesson plans.

3. Ohio River Watershed: This presentation was given by the Executive Director and Chief Engineer of the Ohio Valley Water Sanitation Commission (ORSENCO) and included pollution and water quality monitoring along the Ohio River Basin and its impact. The K-12 outreach programs offered by ORSENCO were described and literature distributed to the teachers, and they were encouraged to avail these opportunities and make their students aware of them.

4. Health Effects of Atmospheric Air Pollutants: This presentation was given by a scientist from the U.S. Environmental Protection Agency's National Risk Management Laboratory on the historical air pollution data for Cincinnati and the regulatory actions taken. The teachers were made aware of the Websites from which they could download air pollution data and the opportunities to use this information to construct interesting lesson plans and activities were discussed.

5. Role of Structural Engineering in Civil Engineering and Structural Engineering as a Profession: This seminar was given jointly by two professional structures engineers. They presented the discipline of structural engineering through the projects they and their companies are involved with. They discussed how the projects evolved and showed pictures. They presented ideas for lessons and hands-on activities in which structural engineering could be used as a context for teaching mathematics and science. They also presented outreach projects being executed by the Cincinnati Section of the American Society of Civil Engineers.

6. Environmental Engineering and the Capacity Assurance Program Plan for Metropolitan Sewer District of Greater Cincinnati: This seminar was given by an engineer for the Water Business Group of CH2M HILL, Cincinnati, Ohio on how storm water collection systems are planned, designed, and constructed. Actual storm water data was presented and its application to evaluate alternative pipe-network systems as part of a water treatment facility. 
The mathematics of the process, with teachers using worksheets along the way, was explained to the teachers familiar.

7. Geotechnical Engineers - Solvers of Landslide and Other Problems: This seminar was given by the Chief Engineer from Richard Goettle, Inc., Cincinnati, Ohio and showcased a novel technique developed by their company for "permanent soil nail retaining walls" as an example to illustrate how geotechnical engineers solve landslide problems. The science behind the concept was illustrated, the mathematics involved in the design calculations was presented, and the construction process used for the retaining wall systems was explained with pictures. This seminar illustrated how science and mathematics are integrated in engineering design and how the technology is transferred into the practice of engineering. Pictures of various other projects executed in the greater Cincinnati area were presented with ideas how these could be used as a backdrop to teach STEM lessons.

8. Role of Construction Engineering in Civil Engineering: Project Management and Scheduling: This seminar was given jointly by the Project Executive and Estimator/Project Manager from Messer Construction Co., Cincinnati, Ohio. They presented the different aspects of construction engineering which included the management of major civil engineering projects and estimation and bidding process. They showed pictures of recent and ongoing projects, and construction drawings which included details used for preparing estimates and bids. They showed actual construction bid packages. Their presentation included lesson examples the teachers could use in their mathematics classes, which included real-world data and exercises using spread sheet software to present results in tabular and graphical form for interpreting various alternative solutions.

9. Transportation Engineering and Reclaiming Our Arterial Streets: This seminar was presented by a traffic engineering and planning consultant who also teaches on a part-time basis. The presentation on included how traffic, roadway, and driver characteristics information are used to conduct traffic flow studies, design of roadway profiles, and operation of traffic control systems. Design of horizontal and vertical curves were presented which the teachers could incorporate in geometry class. Results of a speed delay study, which showed the importance of arterial streets in planning traffic routes in Cincinnati, was presented and discussed how this information could be incorporated in mathematics classes taught by the teachers.

Teachers bring a wealth of knowledge and are encouraged to interact as team members by sharing their expertise with all participating teachers and professionals. The following educational seminars are developed to elicit teacher participation in planning the implementation of RET in their classrooms and to assist teachers in rethinking and strengthening assessment skills:

1. NSF GK-12 Fellows Science and Technology Enhancement Project (STEP) - How the Urban City Theme Can be Used as a Context to Teach Authentically - the Role and Responsibilities of the Teachers: In this two-day seminar the goals, objectives, theme, and roles and responsibilities of the different constituents the current Track 1 (July 2001 to June 2006) and the planned Track 2 (July 2006 to June 2011) of the NSF GK-12 
Fellows STEP were presented to the RET teachers, and the teachers were asked to respond to the question: "What are the factors necessary to negotiate the implementation in your classroom?" In Track 1 Project STEP 28 students (18 graduate and 10 undergraduate) brought their training and experience into 4 urban and 3 suburban schools in 3 Cincinnati school districts. Individual and group activities for $7^{\text {th }}-12^{\text {th }}$ grade students included lesson plans, demonstrations, lab exercises, and field experiences. With this STEM educational system in place, Track 2 Project STEP -- a partnership of UC faculty and 5 graduate Fellows, 5 strategically chosen high schools, and community and industrial partners -- strives to further improve STEM interest and skills of high school students using engineering as a context for authentic learning through an overarching project, "Building STEMcinnati City." Whereas Track 1 Project STEP primarily focused on training the Fellows to become proficient in teaching math and science using authentic practices, Track 2 Project STEP will further address state-of-the-art developments in cognitive science as identified by the $\mathrm{NRC}^{14}$. The vision for Track 2 Project STEP includes facilitating and reinforcing learning through thematically based hierarchical and expandable projects/modules/lessons (together called "activities") in challenging and advanced STEM topics that explicitly connect key concepts of the problems of a city (called "STEMcinnati") across grades 9-12. Fellows will work with a cohort of math and science teachers who collectively teach a group of students that move from one grade to the next. We also plan to integrate social issues related to "how changing technologies impact an urban environment." The overarching focus of the city enables a learnercentered environment that matches students' understanding of their surroundings with the introduction of new fundamental knowledge; a knowledge-centered environment that emphasizes the accuracy and quality of knowledge content; an assessment-centered environment that provides opportunities for feedback through formative assessment and standardized test scores; and a community-centered environment that recognizes effective learning is contextualized within one's own environment. We are using the engineering design of the components of a city to link basic STEM skills and social awareness in the context of student lives. Such metacognitive strategies improve comprehension ${ }^{15,16}$ and the application of knowledge to new scenarios ${ }^{17}$. Our definition of authentic teaching and learning involves an awareness of students' culture, process skills, interests, and goals in order to produce pedagogically sound and engaging activities. These lessons encourage and affirm learning by accessing prior knowledge and relating it to real-world math and science dilemmas, requiring inquiry-based critical thinking to examine problems from multiple perspectives and student collaboration to find a realistic solution.

2. Rubrics/Alternative Assessment: Discussion of traditional and alternative assessments was held. It focused on performance- based assessments, including examples and guidelines for developing scoring rubrics.

3. Objective Tests: A discussion of traditional assessments included a brief background of objective test items, their advantages and disadvantages was presented. It focused on how to write objective tests containing multiple-choice, matching, and alternate-choices items. 
4. Subjective Tests: A discussion of traditional assessments included a brief background of subjective test items, their advantages and disadvantages were presented. It focused on how to write subjective tests including short-answer and essay items.

Each teacher was given opportunities to practice each of the three kinds of assessments.

When the RET Site was being executed a NSF GK-12 Fellows project was also ongoing, in which five graduate Fellows were continuing from previous year and three new engineering graduate Fellows were selected, who were participating in their educational training course. The teachers interacted with these Fellows to: 1) make them more aware of the Cincinnati Public School system, curriculum, classroom management, and cultural issues; 2) critiquing their microteaching lessons; 3 ) viewing the Fellow teaching portfolios and lesson plans available on the web; 4) discussing and collaborating on ideas for new hands-on engineering activities for next year; 5) working with WebQuest hands-on computer lessons; and 6) searching and planning on publication and grants with the teachers.

\section{Assessment}

A mixed method employing both quantitative and qualitative data analysis was used to conduct the assessment. There were multiple criterion measures involved in the evaluation of the effectiveness of the project to determine the overall success of the teacher-faculty partnership and research projects, and ultimately how it will impact secondary school math and science education through changes in teacher pedagogy. In this paper only the results from the first and the second criteria will be presented since the third one will still being conducted during the 2005-2006 academic year. The project evaluation plan includes assessment of the impact of the research experience on the teacher, his/her work in the classroom and subsequent student learning. For the assessment plan Table 1 (see next page) presents the project goals, the key question to be asked regarding the goal, and the instruments used in the evaluation.

All constituencies identified in the project were involved in the assessment: teachers, university instructors, faculty mentors, Graduate Research Assistants (GRA), and the students of teachers. Baseline data on attitudes and instruction practice, as well as general demographics of each constituency, were collected at the beginning of the project and periodically throughout the project, and at conclusion. The overall project effectiveness involved both formative and summative evaluation. Annual summative evaluations served as the basis of the formative evaluation for the subsequent year. Project impact will be determined through data collected and compared in pre-post measures. The overall project effectiveness is based upon the teachers participation and satisfaction with their participation in the summer course and research projects; the faculty mentor and GRA feedback regarding the research projects; the impacts on teaching strategies; and impacts on student learning. Assessment of the impact and learning on teachers were conducted through course assessments; investigation of the impact on teacher's pedagogy and curriculum; using various products they generate through the research projects; and the university instructor evaluations. Assessment of the impact and learning on the students of these teachers were conducted through the collection of student learning portfolios; OGT test results; impact on teacher's pedagogy and curriculum; and classroom observations and evaluations. 
Table 1. Assessment Instruments Used

\begin{tabular}{|c|l|l|}
\hline Goal & \multicolumn{1}{|c|}{ Key Question } & \multicolumn{1}{c|}{ Instruments } \\
\hline I & $\begin{array}{l}\text { To what extent did the RET } \\
\text { program empower teachers to use } \\
\text { inquiry and critical research skills } \\
\text { to solve real world science } \\
\text { problems in their classroom? }\end{array}$ & $\begin{array}{l}\text { Prior exposure to engineering research } \\
\text { questionnaire; Course assessments; Evaluation of } \\
\text { posters, papers, presentations; lessons, Teacher } \\
\text { feedback/satisfaction survey; Daily logs (journals); } \\
\text { Self-efficacy \& attitudes survey; Faculty mentor } \\
\text { rating scale; GRA rating scale; Research training } \\
\text { environment scale, journal writings. }\end{array}$ \\
\hline II & $\begin{array}{l}\text { To what extent do the teachers } \\
\text { share skills learned in RET with } \\
\text { students and colleagues? }\end{array}$ & $\begin{array}{l}\text { Tracking form; Pre-post classroom observations; } \\
\text { Curriculum/Instruction Inventory; Teacher } \\
\text { feedback/satisfaction survey; Papers/presentations; } \\
\text { Website material, journal writings. }\end{array}$ \\
\hline III & $\begin{array}{l}\text { How does the RET program } \\
\text { impact learning in the science } \\
\text { and math classrooms? }\end{array}$ & $\begin{array}{l}\text { Skills/confidence inventory; Course assessments; } \\
\text { OGT results; Student learning portfolios; Pre-post } \\
\text { classroom observation; Pre-post student subject } \\
\text { preference inventory; Teacher post project } \\
\text { interviews; Pre-post student attitude surveys, } \\
\text { journal writings. }\end{array}$ \\
\hline
\end{tabular}

Figure 1 (see next page) schematically illustrates the complete assessment process, the constituencies involved in collecting the data and those that will be impacted from the results, and how the assessment results will be used to document the outcomes of the project.

\section{Results and Conclusions}

Data from quantitative and qualitative instruments demonstrate the impact of the grant to help teachers excite students to learn and the extent to which related goals have been realized. Teachers have shown an increased appreciation and understanding of the scientific method of inquiry and the critical research skills that engineers use to solve open-ended real-world problems. They have shown an increased wiliness to become role models by applying their research experiences in their classrooms and with colleagues. Teachers have also shown an increase in skill and understanding on how to directly link their education to events and issues occurring within their community. Findings were supported by multiple sources of data including: Teacher Focus Group, Teacher Feedback Forms, Teacher Weekly Journals, Evidence of Lesson, Presentations by Teachers, Technical Report written by Teachers, and Attitudinal and Confidence Surveys.

Four female, secondary teachers participated in the six week summer program. All four teachers had graduate degrees; two were secondary mathematic teachers; two were secondary science teachers. While the low number of participants may be a detriment to the study, significant results were realized through the data analysis. The results will be merged into a multi-year study as the program is expanded. The gains for each of the project goals are summarized in Table 2 (see page after next). 


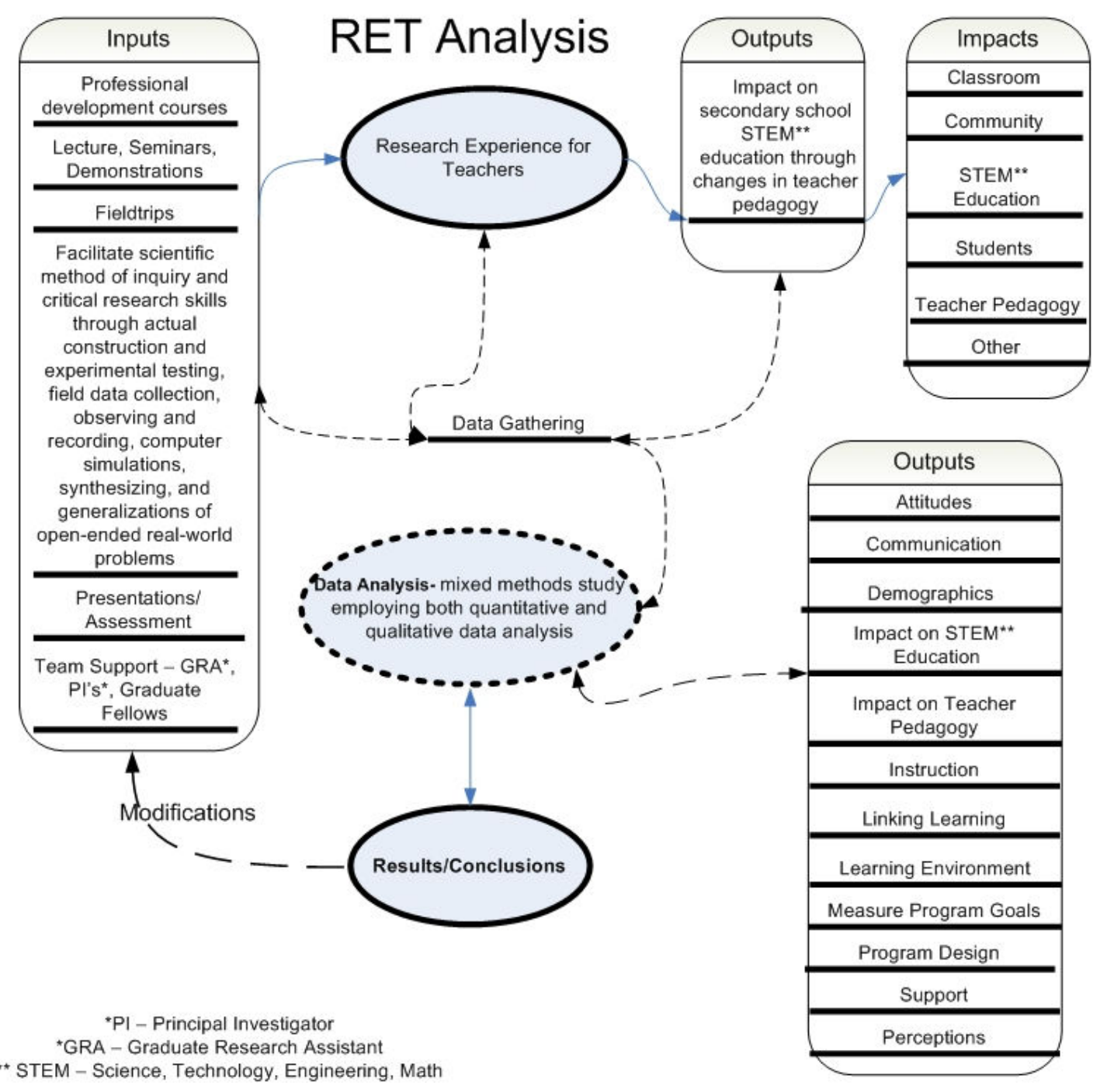

\section{Figure 1. RET Assessment Process Planned}

Teachers experienced research and developed authentic learning activities and have become familiar with the importance of the scientific method of inquiry and the critical research skills that engineers use to solve open-ended real-world problems. They learned practical considerations of research, lesson planning and presentation. They have shown an increased understanding of skills required and their own confidence in using skills. They have also shown an increase in skill and understanding on how to directly link their education to events and issues occurring within their community. Two teacher comments received from the feedback form are presented below:

"This was the one experience that I hoped to gain from my experiences this summer. I definitely have a better understanding and ability to link what my students are doing in the classroom to real world science and mathematics problem solving." 
Table 2. Mapping of the Teacher Gains with Project Goals

\begin{tabular}{|c|c|c|}
\hline Goal & Key Question & Teacher Gains \\
\hline $\mathrm{I}$ & $\begin{array}{l}\text { To what extent did the RET } \\
\text { program empower teachers to use } \\
\text { inquiry and critical research skills } \\
\text { to solve real world science and } \\
\text { math problems in their } \\
\text { classroom? }\end{array}$ & $\begin{array}{l}\text { - } \text { Gained knowledge of technical } \\
\text { - } \quad \text { information. } \\
\text { - } \quad \text { Learned to take data for what it is. } \\
\text { - } \quad \text { Learned variety of fields of } \\
\text { engineering } \\
\text { - } \quad \text { Learned science is a discipline } \\
\text { - } \quad \text { Learned development of rubrics and } \\
\text { - } \text { assessments } \\
\text { - } \quad \text { Coarned how engineers work } \\
\text { - } \text { Improved, more effective lessons } \\
\text { - } \quad \text { Team approach in project exceeded } \\
\text { expectations }\end{array}$ \\
\hline II & $\begin{array}{l}\text { To what extent do the teachers } \\
\text { share skills learned in RET with } \\
\text { students and colleagues? }\end{array}$ & $\begin{array}{l}\text { - } \text { Teams } \\
\text { - Staff Meetings } \\
\text { - Presentations } \\
\text { - Showing } \\
\text { - Modeling } \\
\text { - Sharing flyers, booklets } \\
\text { - Ambassador for program } \\
\text { - Share with other buildings in district }\end{array}$ \\
\hline III & $\begin{array}{l}\text { How does the RET program } \\
\text { impact learning in the science and } \\
\text { math classrooms? }\end{array}$ & $\begin{array}{ll}\text { - } & \text { Will share floating riverboat project } \\
\text { - } & \text { Fieldtrips } \\
\text { - } & \text { Knowledge of engineering fields } \\
\text { - } & \text { Guest speakers } \\
\text { - } & \text { Service learning projects after field of } \\
\text { - } & \text { study } \\
\text { Effective Lessons }\end{array}$ \\
\hline
\end{tabular}

"The most rewarding experience was meeting all the fellows, grad students and professors and engineering professionals. I think the contacts made are invaluable. I also think the field trips we took were very helpful because now we have contacts and places thought about that we can take our students to. I think the information that I gained from all the engineers just about what different types of engineers do was invaluable too."

Analysis of the grant was not only on goal attainment. The grant analysis revealed the areas of attitudes, communication, demographics, and perception of participants; instruction, learning environment, overall program components, and support design; and the ability of the grant to link learning experiences/partnerships between participants needed serious review. The 
analysis revealed strengths and weakness of the grant in all categories. The analysis broke down the data into categories of what worked, what needed tweaking, and what needed fixing in the implementation of the grant for expanded years.

Main areas of "what worked" included the learning environment, linking of learning experiences/partnerships, instruction, and support. Teachers indicated an appreciation of the learning environment. They showed an appreciation in the contacts made with professors, seminar participants, Fellows, and GRA. They indicated they saw value in linking engineering and real-world projects into lesson plans. The teachers demonstrated higher levels of understanding of inquiry lesson development, assessment creation, and an in depth knowledge of the various fields of engineering. All participants indicated that the support team exceeded their expectations.

Main areas of "what worked" included the learning environment, linking of learning experiences/partnerships, instruction, and support. Teachers indicated an appreciation of the learning environment. They showed an appreciation in the contacts made with professors, seminar participants, Fellows, and the Graduate Research Assistants. They indicated they saw value in linking engineering and real-world projects into lesson plans. The teachers demonstrated higher levels of understanding of inquiry lesson development, assessment creation, and an in depth knowledge of the various fields of engineering. All participants indicated that the support team exceeded their expectations.

Areas of "fix" included communication and program design. Teachers indicated that they were pressured to give honest input in weekly journals. They indicated that they expected appropriate responses to the journals as a result of the added pressure to give honest input, but felt that they did not receive it. Teachers stated they were short on time at end of six weeks and had to rely on team members to finish all tasks. They indicated pacing of the schedule of the six week program needed to be rethought to start participants on tasks faster.

The evaluation continues on into the school year to assess effect of teacher exposure to RET on student learning. The analysis of this data will be integrated into the current findings.

\section{Acknowledgments}

The authors would like to acknowledge the financial support provided by the National Science Foundation for the Award No. DGE-0139312, and cost sharing funds provided by the Southwest Ohio Center for Excellence in Science and Mathematics Education at University of Cincinnati. The assistance provided by the Cincinnati Section of the American Society of Civil Engineers in organizing the engineering seminars for the teachers is greatly appreciated. The authors acknowledge the teachers, Terri Bennett, Sharon Bachman, Laura Monti, and Emma Massie, who participated in the RET project. The assistance provided by the Graduate Research Assistant mentors and the STEP Fellows, Amy Dimmerling, Sarah Pumphrey, Zifei Liu, Manojkumar Pavithran, Priyatham Konda, Jim Allen, Bethany Vice-Bowling, Michelle Daniel, Matthew Estes, Bartley Richardson, and Mike Rust, is appreciated. 


\section{Bibliography}

1. Business-Higher Education Forum. (2002). "Investing in People: Developing All of America's Talent on Campus and in the Workplace." American Council on Education, Washington, D.C.

2. National Commission on Teaching and America's Future. (1996). "What Matters Most: Teaching for America's Future," Report of the National Commission on Teaching and America's Future, Woodbridge, VA, 22194-5239.

3. Ingersoll, R.M. (1999). "The problem of Underqualified Teachers in American Secondary Schools." Educational Researcher, March, Vol. 28, No. 2, pp. 26-37.

4. National Commission on Math and Science Education for the $21^{\text {st }}$ Century. (2000). Before It's Too Late: Math And Science Teaching In The Twenty-First Century, Glenn Commission Report EE0449P, Washington, DC, September.

5. National Council on Teacher Quality. (2001). Teacher Quality Bulletin, Vol. 2, No. 28, July 9.

6. Darling-Hammond, L. (2000). "Teacher Quality and Student Achievement: A Review of State Policy Evidence," Education Policy Analysis Archives, Vol. 8, No. 1, available at: http://epaa.asu.edu/epaa/v8.

7. Ingersoll, R.M. (2002). "The Teacher Shortage: A Case of Wrong Diagnosis and Wrong Prescription," NASSP Bulletin, Vol. 86 No. 631, June, http://www.principals.org/news/bltn teachshort0602.cfm (also published in the Fall 2001 issue of the American Educational Research Journal).

8. Yee, B.S. (1997). "A Sanctuary for Mobile Agents," DARPA Workshop on Foundations for Secure Mobile Code, February.

9. Pennell, J. R., and Firestone, W. A. (1996). "Changing Classroom Practices Through Teacher Networks: Matching Program Features with Teacher Characteristics and Circumstances," Teachers College Record, Vol. 98, No. 1, 46-76.

10. Lieberman, A, and Grolnick, M. (1996). "Networks and Reform in American Education," Teachers College Record 98, No. 125.

11. Sparks,D. (1995). "Focusing Staff Development on Improving Student Learning," in Handbook of Research on Improving Student Achievement, ed. G. Cawelti, pp. 163-172, ERIC, ED 394629.

12. Little, J.W. (1993). “Teachers' Professional Development in a Climate of Educational Reform," Educational Evaluation and Policy Analysis, Vol. 15, pp. 129-151.

13. Levin, D., Knezek, D., Conery, L., and George, M. (2004). National Educational Technology Plan. Washington, DC: US Department of Education.

14. National Academy Press. (2002). How People Learn: Brain, Mind, Experience, and School, Fifth Printing, P374. Editors: Bransford, J. D., Brown, A., and Cocking, R.

15. White, B.Y., and Fredrickson, J.R. (1998). "Inquiry Modeling and Metacognition: Making Science Accessible to all Students", Cognition and Science, Vol. 16, pp. 90-91.

16. Schoenfeld, A.H. (1991). "On Mathematics as Sense Making: An Informal Attack on the Unfortunate Divorce of Formal and Informal Mathematics," Informal Reasoning and Education, Editors: J.F. Voss, D.N. Perkins and J.W. Segal eds., Hillsdale, and NJ: Eribaum, pp. 331-343.

17. Palincsar, A.S., and Brown, A.L. (1982). "Reciprocal Teaching and Comprehension Monitoring Activities," Cognition and Instruction, Vol. 1, pp. 117-175. 